\title{
La determinación de potencialidades agropecuarias y silvícolas en zonas de montaña. Municipio Buey Arriba. Cuba
}

The determination of agricultural and forest potentialities in mountains areas. Municipality of Buey Arriba. Cuba

\author{
Adonis M. Ramón Puebla \\ Magíster en Geografía, Medio Ambiente y Ordenamiento Territorial \\ Órgano de Atención al Desarrollo Integral de la Montaña Sierra Maestra, CITMA. \\ Granma, Cuba \\ Correo electrónico: omsm@granma.inf.cu

\section{Eduardo Salinas Chávez} \\ Doctor en Ciencias Geográficas, Profesor Titular de la Universidad \\ de La Habana, Cuba. \\ Profesor Invitado, Universidade Federal da Grande Dourados, MS, Brasil. \\ Correo electrónico: esalinasc@yahoo.com

\section{Leusnier Martínez Quintana} \\ Ingeniero Forestal, Órgano de Atención al Desarrollo Integral de la Montaña Sierra \\ Maestra, Granma, Cuba \\ Correo electrónico: omsm@granma.inf.cu

\section{Célida Suarez García} \\ Ingeniera Forestal, Órgano de Atención al Desarrollo Integral de la Montaña Sierra \\ Maestra, CITMA, Granma, Cuba \\ Correo electrónico: omsm@granma.inf.cu
}

Resumen: la entrega en usufructo de tierras ociosas para la producción de alimentos en el municipio Buey Arriba, no siempre toma en cuenta las potencialidades reales del territorio, ni las regulaciones y normas ambientales vigentes para la ocupación de dichos espacios. Esta investigación parte de la obtención de mapas de cobertura vegetal, la modelación en SIG de las variables y el análisis de las regulaciones ambientales vigentes para cada uso propuesto. Ofreciendo para el municipio un escenario de sus potenciales agropecuarios y silvícolas con vistas a su adecuado aprovechamiento en función de la producción de alimentos, determinándose que el territorio, a pesar de ser montañoso en un $80 \%$, cuenta con lugares adecuados para este desarrollo sin comprometer la protección del medio ambiente.

Palabras clave: potenciales agropecuarios, potenciales silvícolas, modelación SIG, producción de alimentos, protección ambiental.

Abstract: delivery in usufruct of idle land for food production in the Buey Arriba municipality, does not always take into account the real potential of the territory, or existing environmental regulations and standards for the occupation of these spaces. 
Adonis M. Ramón Puebla Eduardo Salinas Chávez Leusnier Martínez Quintana

MSc. Célida Suarez García

The research parts from the gathering of land cover maps, GIS modeling of variables and analysis of environmental standards for each intended use. Providing a stage for the township agricultural and forestry potential for appropriate use in terms of food production, determining that the territory, despite of being

Recibido: julio 2017
$80 \%$ mountainous, it has suitable locations for this development without compromising the protection of the environment.

Keyworks: farming potentialities, forestry potentials, GIS modeling, food production, environmental protection.

Aceptado: septiembre 2017

\section{Introducción}

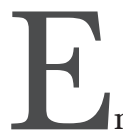

n Cuba las montañas de la Sierra Maestra, constituyen el territorio de mayores contrastes geográficos, donde interactúan lo complejo y lo diverso tanto natural como económico y social. Esta región no sólo presenta limitaciones y dificultades para su asimilación económica, sino que tiene una capacidad para el desarrollo de formas de uso muy particulares en función de sus condiciones geográficas y de su asimilación económica particular, la presencia de un tipo de economía especifica en el contexto regional y los variados y elevados valores ecológicos e histórico-culturales, que a su vez condicionan variantes de asimilación socioeconómica muy diferente a las de las llanuras. En ellas se requiere una asimilación económica muy especializada y en armonía con el medio ambiente.

En estas regiones montañosas como en muchos lugares del país, se precisa el incremento de la producción de alimentos y el aprovechamiento de los recursos forestales, lo que pasa ante todo por el incremento de las áreas productivas, actividad que se encuentra actualmente en pleno auge, a partir del decreto 259, que priorizó la entrega de tierras consideradas ociosas a personas o entidades interesadas en explotarlas hasta una cantidad determinada de hectáreas, este proceso se amplió posteriormente con el decreto 300, que aumentó el área de tierra que puede ser entregada en usufructo a una persona o entidad.

Esta entrega de tierras, es realizada por las Comisiones Agrarias Municipales y muchas veces por el desconocimiento de las potencialidades reales del territorio y otras por el desconocimiento de las regulaciones ambientales vigentes entran en contradicción con los potenciales reales de los diferentes territorios ocasionando que se entreguen tierras para el desarrollo de actividades agroproductivas en zonas que violan normas y regulaciones ambientales vigentes, y en áreas que por factores geográficos y ambientales no son las idóneas para la actividad para la que ha sido solicitada por parte de los productores.

Estos conflictos han sido comprobados en los recorridos de trabajo realizados por varios municipios que se encuentran dentro de la región montañosa de la Sierra Maestra; siendo uno de los casos más complejos el municipio Buey Arriba, un territorio eminentemente montañoso, con una situación complicada a decir de sus decisores para la producción agropecuaria. En este territorio se detectó la entrega de tierras para 
ganadería y cultivos varios en franjas forestales hidroreguladoras de ríos y embalses; así como en zonas que por la inclinación de la pendiente y otros factores edáficos y de relieve, según recomendaciones señaladas en los trabajos realizados por (Benítez, Ramírez, y Machado 2006, Garea, Soto y Vantour 2006 y Ministerio de la Agricultura 2003), no son apropiadas para las actividades a las que se están destinando.

A partir de estos análisis con las entidades responsables y la Comisión Agraria del Municipio se determinó que no existen los conocimientos adecuados sobre las potencialidades naturales del municipio y los sitios apropiados para el desarrollo de las distintas actividades agropecuarias y silvícolas, surgiendo así la necesidad de dotar a los decisores del territorio del estudio y la cartografía básica del territorio a partir de las posibilidades que ofrece el análisis de imágenes de satélite y el uso de los Sistemas de Información Geográfica (SIG), que sirvan de base para la entrega de tierras de acuerdo con las potencialidades reales del lugar y la rectificación del destino de las parcelas de tierra que ya han sido entregadas.

La fundamentación metodológica de este trabajo se basa en la concepción del potencial de las tierras empleado por diversos especialistas y organismos internacionales desde hace algunas décadas y que forma parte de una amplia concepción de los estudios complejos y de síntesis del territorio, que fue desarrollada de forma destacada por los geógrafos alemanes en la llamada "Escuela del Potencial" cuyos más importantes exponentes fueron Haase (1991) y Mannsfeld (1983). Esta concepción además guarda relación con la Planificación Ecológica de los franceses y con los estudios de vocación del suelo de los norteamericanos y que puede ser definido como: "la capacidad productiva, informativa y regulativa de los paisajes según la asociación de determinadas posibilidades y condiciones actuales para diferentes tipos de utilización, con el objetivo de satisfacer las necesidades de la sociedad" (Salinas, 1991).

Definiéndose para este trabajo el potencial agrícola y silvícola como "aquellos territorios que por sus características generales y elementos específicos (pendiente, suelo, altura, humedecimiento, etc.) presentan valores destacados que permiten el uso agrícola con altos niveles de productividad y eficiencia, sin que ello conlleve a su degradación y la perdida de otros valores de importancia como son: calidad del agua, suelos, etc.” (Salinas, Yanes y Arceo, 1990 y Arceo y Salinas, 1994).

Las técnicas de trabajo aquí propuestas se basan en la amplia difusión y aplicación de la Percepción Remota y su aplicación a estudios ambientales la cual está avalada por múltiples trabajos, como el de Pompa (2008), que realiza un análisis de la deforestación en ecosistemas montañosos del noreste de México; las especificaciones técnicas que da (CONAFOR, 2007) para el monitoreo de la cobertura de la vegetación basado en imágenes de satélite MODIS y otras.

Los SIG también tienen una larga historia en los estudios territoriales y ambientales y permiten el procesamiento, análisis y cartografía de diversos fenómenos y procesos naturales, económicos y sociales y su distribución espacial, siendo considerados como un sistema de información complejo de gran eficacia, capaz de dar respuestas a cuestiones actuales del uso de los territorios, así como orientar futuras actuaciones de agentes públicos y privados, facilitando la toma de decisiones que afectan al medio ambiente (Bosque, 1996; Buzai y Baxendale, 2012 y Miraglia, Caloni y Buzai, 2015).

En este sentido el presente trabajo pretende determinar en función de la legislación 
Adonis M. Ramón Puebla Eduardo Salinas Chávez Leusnier Martínez Quintana MSc. Célida Suarez García

ambiental cubana, así como de un conjunto de factores geográficos y ambientales el potencial agropecuario y silvícola del municipio Buey Arriba, así como las áreas con aptitud para la reforestación, basándose en las posibilidades que pueden brindar la interpretación de las imágenes satelitales en combinación con los SIG.

\subsection{Características del área de estudio}

El municipio Buey Arriba con una extensión de 48204.50 ha, considerado como montañoso en aproximadamente un $80 \%$, se localiza en la parte norte de la provincia Granma, en la ladera norte del macizo montañoso de la Sierra Maestra (ver figura 1), caracterizado según datos tomados de Viña-Dávila, et al. (2000) por la presencia de una llanura aluvial al norte del municipio que va transicionando a llanura premontañosa hacia la parte sur del municipio, donde comienzan alturas y montañas que oscilan desde los 200 hasta más $1700 \mathrm{~m}$ de altura; desde el punto de vista climático la región está bajo la influencia de los vientos Alisios con humedecimiento alto y estable, baja evaporación y temperaturas frescas.

La hidrografía es rica y variada formada en lo fundamental por un río principal (Buey), nueve ríos de primer orden (Buey del Yao, Montero, Los Robles, Palmarito, la Olla, California, Macio, Bernabé y Mabay) y más de treinta de segundo y tercer orden, así como la presencia de dos embalses (Buey y Pedregales) y una micropresa, todos destinados al uso agrícola.

La cubierta de suelos, está caracterizada fundamentalmente por la presencia de suelos Pardos Sin Carbonatos (44.2\% del territorio) en las zonas llanas y premontañosas y Ferralítico Rojo Lixiviado $(33.2 \%)$ en zonas con fuertes pendientes asociadas a las montañas bajas y medias. En menor medida se encuentran los suelos Ferralítico Amarillento (6.3\%), Esquelético (6.1\%), Aluvial (2.9\%), Fersialítico Pardo Rojizo (2.6\%), Pardo Con Carbonatos (2.4\%), Oscuro Plástico No Gleyzado (2\%) y Húmico Carbonatico $(0.1 \%)$. 


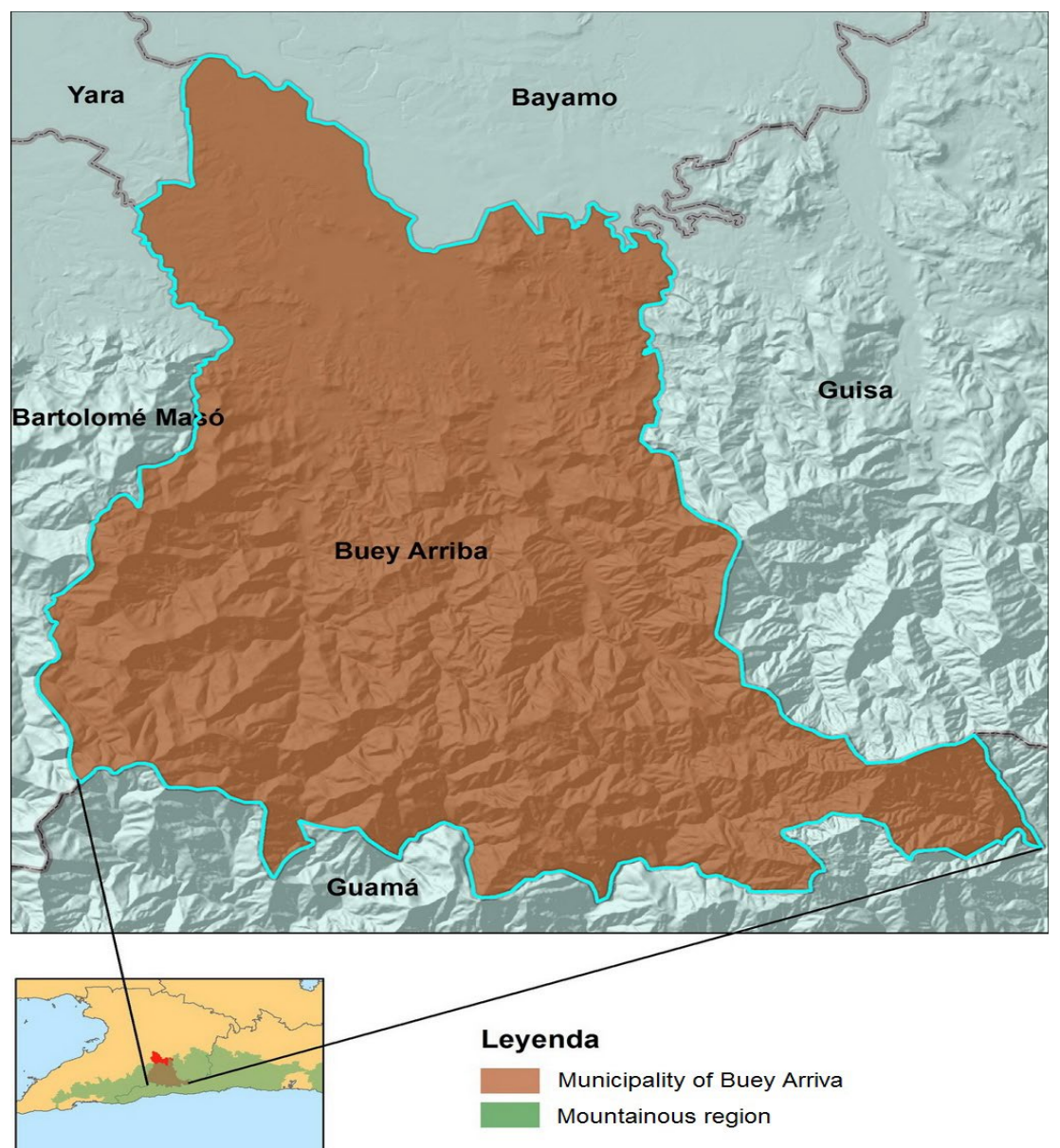

Figura 1. Situación geográfica del municipio Buey Arriba Fuente: Elaborada por los autores.

La vegetación, está formada en un 54.7\% por bosques que van desde los semicaducifolios en las zonas más bajas hasta el monte nublado y la pluvisilva montana en las montañas más elevadas, el resto de la vegetación lo constituyen, bosques degradados (5.5\%) cafetales (11.9\%), matorrales espinosos (fundamentalmente Marabú) y no espinosos derivados de la degradación de las áreas boscosas y el abandono de zonas de cultivos y pastizales (12.9\%); y en menor medida áreas de cultivos y pastizales en las zonas llanas de mayor agroproductividad y en algunas zonas de fuertes pendientes $(8.8 \%)$, así como áreas de frutales $(0.4 \%)$ en las zonas más llanas.

\section{Metodología}

El procedimiento para la determinación de los potenciales agrícola y silvícola se realizó mediante el análisis de las variables consideradas como limitantes para el 
Adonis M. Ramón Puebla Eduardo Salinas Chávez Leusnier Martínez Quintana MSc. Célida Suarez García

aprovechamiento económico de un territorio y buscando que el uso del mismo se adecue a las regulaciones aprobadas en el país al respecto, realizando para ello el análisis de las variables: inclinación de la pendiente, fertilidad natural de los suelos y cobertura forestal actual, posteriormente se determinó la faja forestal hidroreguladora de los embalses, ríos y arroyos del territorio y las áreas declaradas de protección con categorías de manejo estricto, a continuación se modelan las regulaciones y la legislación ambiental relacionada a estas áreas y finalmente se realiza el análisis integrado de estas variables como se ilustra en la figura 2.

Generación del mapa de pendientes: el mapa de pendientes se generó a partir del Modelo Digital del Terreno 1:25 000 del territorio, con un pixel de 25 metros, tomando como base los rangos de pendientes establecidos como limitantes para el uso agrícola y forestal en la Ley No 85 "Ley Forestal" y la Norma Cubana 66 del 2000, "Calidad del suelo. Suelos forestales. Utilización y clasificación", la cual establece para la silvicultura de producción y protección en Cuba, el tipo de suelo e intervalo de pendiente para los suelos montañosos y premontañosos, donde el factor limitante es la pendiente; y las limitantes y rangos para los distintos cultivos en zonas montañosas que se establecen a partir del Manual Técnico para las actividades agropecuarias y forestales en las montañas del Ministerio de la Agricultura (2003).

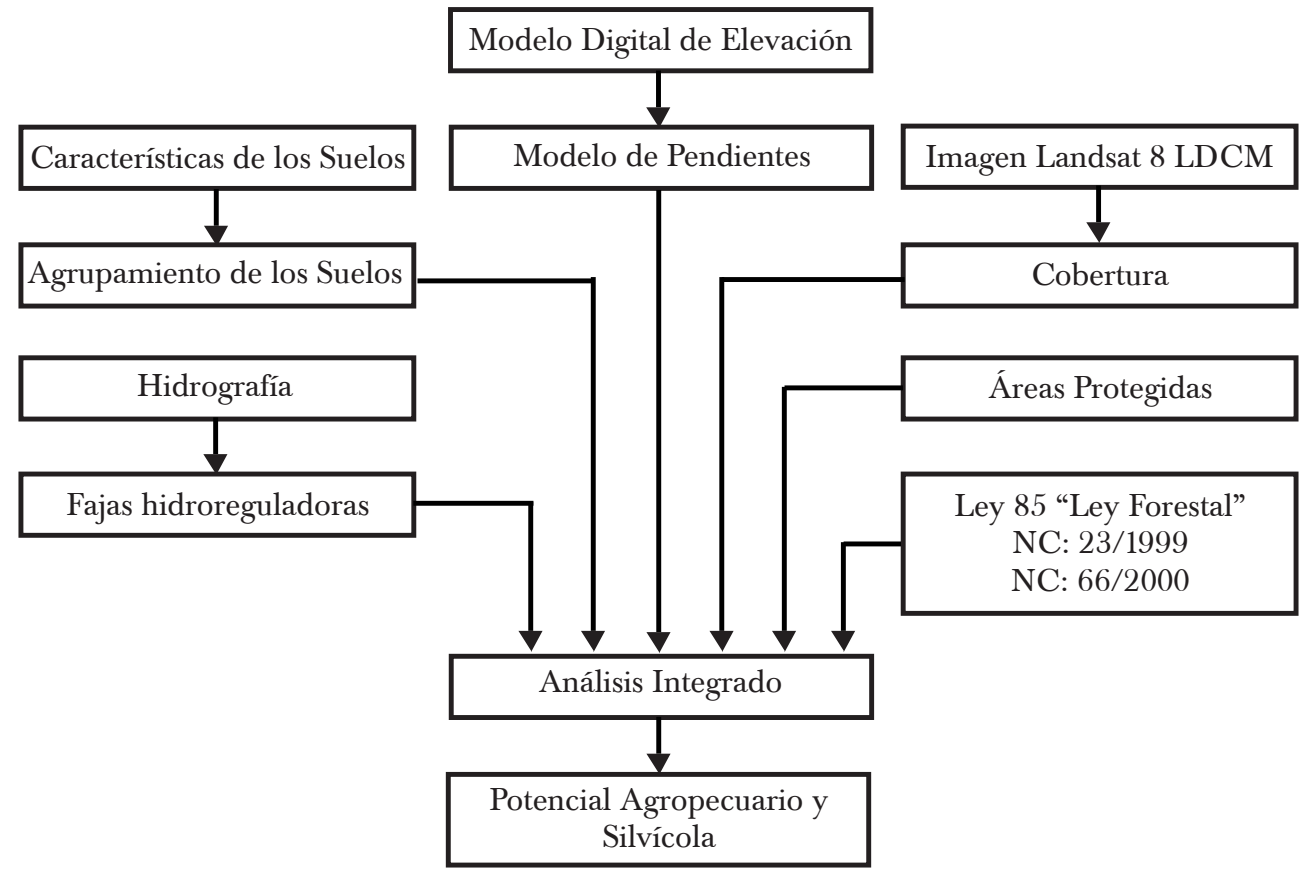

Figura 2. Procedimiento metodológico para la determinación de los potenciales agropecuario y silvícola.

Fuente: Elaborada por los autores 
Agrupación de los suelos en función de su fertilidad: los tipos de suelos fueron agrupados para facilitar los análisis de superposición en los SIG en función de sus características en dos categorías: fértiles o poco fértiles, a partir de la información obtenida del mapa de suelo 1:25 000 del municipio (tipo, profundidad, pH, lavado, erosión y agroproductividad) lo cual permite de forma general establecer el uso adecuado del suelo para una u otra actividad en función de dichas características.

Determinación de la cobertura vegetal predominante: la cobertura actual del territorio se determinó a partir de las imágenes satelitales Landsat 8 LDCM del 2014, con un pixel de 30 metros, formadas por bandas independientes en formato tiff, de las cuales son tomadas las bandas 2,3 y 4 para generar un solo archivo y hacer posible su manipulación con el software ERDAS 2011, mediante la aplicación de técnicas de clasificación digital tanto del tipo no supervisado (por isodata) como supervisado para la determinación de la cobertura forestal. Lo cual implica una fase de edición de firmas o muestreo de pixeles de entrenamiento y una fase de asignación con apoyo de información de campo.

Determinación de las fajas hidroreguladoras de los embalses y ríos: las fajas hidroreguladoras se determinaron a partir de la red hídrica del territorio para los ríos y embalses principales, mediante la determinación del área buffer (área de influencia) en función de las regulaciones establecidas por la Norma Cubana 23 de 1999 "Fajas forestales de las zonas de protección a embalses y cauces fluviales", que establece el ancho de la faja forestal obligatoria para cada categoría de río y embalse con las dimensiones siguientes:

- En los embalses: $30 \mathrm{~m}$, medidos en proyección horizontal a partir del Nivel de Aguas Máximo (NAM).

- En los ríos principales: 20 m en ambas márgenes, medidas en proyección horizontal, a partir del borde del cauce natural.

- En los ríos de primer orden: 15 m en ambas márgenes, medidas en proyección horizontal, a partir del borde del cauce natural.

- En los ríos de segundo orden en adelante: 10 m en ambas márgenes, medidas en proyección horizontal a partir del borde del cauce natural.

Delimitación de las áreas protegidas del territorio: la delimitación de las áreas protegidas del territorio se obtuvo a partir del inventario existente en el Centro Nacional de Áreas Protegidas y en aquellas áreas que por su categoría se prohíben las actividades agropecuarias, se excluyó el análisis del potencial agropecuario o forestal independientemente de la pendiente o fertilidad natural de los suelos. En este caso fueron identificadas en el territorio dos áreas protegidas de categoría estricta, ambas con la categoría de Parque Nacional: Pico La Bayamesa y Turquino.

Establecimiento de los potenciales para el territorio: para la determinación de los potenciales en el territorio, se hizo una valoración integral de las características climáticas y pedo-geomorfológicas del territorio, la cobertura actual, los tipos de cultivo y actividades agroproductivas y silvícolas tradicionales y no tradicionales que pueden 
Adonis M. Ramón Puebla Eduardo Salinas Chávez Leusnier Martínez Quintana MSc. Célida Suarez García

desarrollarse, quedando excluidas como áreas productivas e incorporándose a las de protección independientemente de la pendiente, aquellas áreas localizadas dentro del sistema de áreas protegidas y las correspondientes a las fajas forestales de las zonas de protección a embalses y cauces fluviales.

\section{Resultados}

Los rangos de pendiente para la determinación del potencial agropecuario (ver tabla 1) se establecieron a partir del Manual Técnico para las actividades agropecuarias y forestales en las montañas del Ministerio de La Agricultura (2003), como sigue:

Tabla 1. Rangos de pendientes para la determinación del potencial agropecuario.

\begin{tabular}{|l|l|}
\hline Rango de pendiente & Uso Potencial Recomendado \\
\hline $0-8 \%$ & Hortalizas, granos y viandas \\
\hline $8-10 \%$ & Malanga, calabaza y boniato \\
\hline $10-25 \%$ & Pastizales para la ganadería \\
\hline $25-30 \%$ & Café, cacao y frutales \\
\hline $30-50 \%$ & $\begin{array}{l}\text { Café, cacao y frutales en suelos óptimos con fuertes } \\
\text { medidas de conservación de suelo. }\end{array}$ \\
\hline
\end{tabular}

Fuente: Elaborada por los autores.

Para la actividad silvícola, se establecieron rangos a partir del análisis de la Ley No 85 Forestal publicada en la Gaceta Oficial de la República de Cuba (1998) y la Norma Cubana 66 del 2000 de Oficina Nacional de Normalización (2000). Ver tabla 2.

Tabla 2. Rangos de pendientes para la determinación del potencial silvícola.

\begin{tabular}{|l|l|}
\hline Rango de pendiente & Uso Potencial Recomendado \\
\hline $0-25 \%$ & Silvicultura mecanizada de producción. \\
\hline $25-50 \%$ & Silvicultura no mecanizada para la producción. \\
\hline$<50 \%$ & Silvicultura no mecanizada para la protección \\
\hline
\end{tabular}

Fuente: Elaborada por los autores.

Establecidos los rangos idóneos para cada actividad se procedió a analizar la variable fertilidad natural de los suelos, recomendándose la actividad agropecuaria para aquellos suelos con buena fertilidad natural y las actividades silvícolas para los suelos poco fértiles.

A continuación, se le resta a las áreas agropecuarias y silvícolas de producción las fajas hidroreguladoras de la red hídrica del territorio para los ríos y embalses, figura 8, determinadas en función de las regulaciones establecidas por la Norma Cubana 23 de 1999 de Oficina Nacional de Normalización (1999). Estableciéndose para los embalses Buey, Pedregales y para la micropresa, una faja forestal de $30 \mathrm{~m}$, en el caso de la red hídrica el buffer establecido es de $20 \mathrm{~m}$ para el río Buey, de $15 \mathrm{~m}$ para los ríos: Buey 
del Yao, Montero, Los Robles, Palmarito, la Olla, California, Macio, Bernabé y Mabay y de $10 \mathrm{~m}$ para el resto de las corrientes fluviales del territorio.

Posteriormente se determinaron los tipos de cobertura a partir del mapa de formaciones vegetales y de la interpretación de la imagen Landsat 8 LDCM del 13/01/2014, sometida a un análisis multiespectral y a la aplicación de reglas de decisión basadas estadísticamente para la identificación de la cobertura de terreno de cada pixel en la imagen. Esta tarea fue acompañada de trabajo de campo para la comprobación en el terreno de los tipos de vegetación identificadas en la imagen satelital, figura 3. Para el caso de los cafetales al no ser posible su identificación por los métodos anteriormente señalados, se procedió a la toma de esta información a partir del mapa de uso del suelo de la provincia Granma del año 2013.

Obteniéndose de este trabajo la distribución de coberturas siguiente: 26495.1 ha de distintos tipos de bosques; 2675.7 de bosques degradados; 5720.1 ha de cafetales; 4360.8 ha de cultivos, pastizales naturales y herbazales; 6528.8 ha de matorrales y vegetación arbustiva, fundamentalmente Marabú (Dichrostachys cinerea); 1628.0 ha de superficie hídrica; y 799.8 ha de zonas urbanas y asentamientos de población.

Finalmente se procede a realizar la superposición de las distintas capas en el SIG y el análisis de todas las variables obtenidas, con lo cual se establece para cada sector del municipio las potencialidades agrícolas y silvícolas, dándole mayor prioridad a aquellas relacionadas con la producción de alimentos. Siempre dando un margen de flexibilidad en los tipos de actividades recomendadas, siendo posible establecer en una unidad de bajo porciento de pendiente cualquiera de las actividades que se encuentran por debajo de ella en cuanto a porciento de inclinación de la pendiente, no recomendándose este comportamiento a la inversa. Es decir, se puede establecer cafetales en pendiente de $0-8 \%$, pero no se recomienda cultivar hortalizas viandas y granos en sectores con pendientes de $25-30 \%$.

Es pertinente aclarar, que este estudio se llevó hasta el nivel de Consejo Popular, cuyos límites son reflejados en el mapa de la figura 3. El Consejo Popular, constituye dentro del municipio, la unidad inferior de la división político-administrativa para numerosos organismos en tareas organizativas y de administración de los recursos; razón por la cual fue determinada de forma independiente para cada uno de estos su potencial agropecuario y silvícola existente. La figura 3, muestra la distribución de los potenciales agropecuario y silvícola obtenidos para el municipio Buey Arriba. En la leyenda se encuentran codificados por números y colores las potencialidades descritas en el territorio; su área y demás datos se detallan a continuación: 


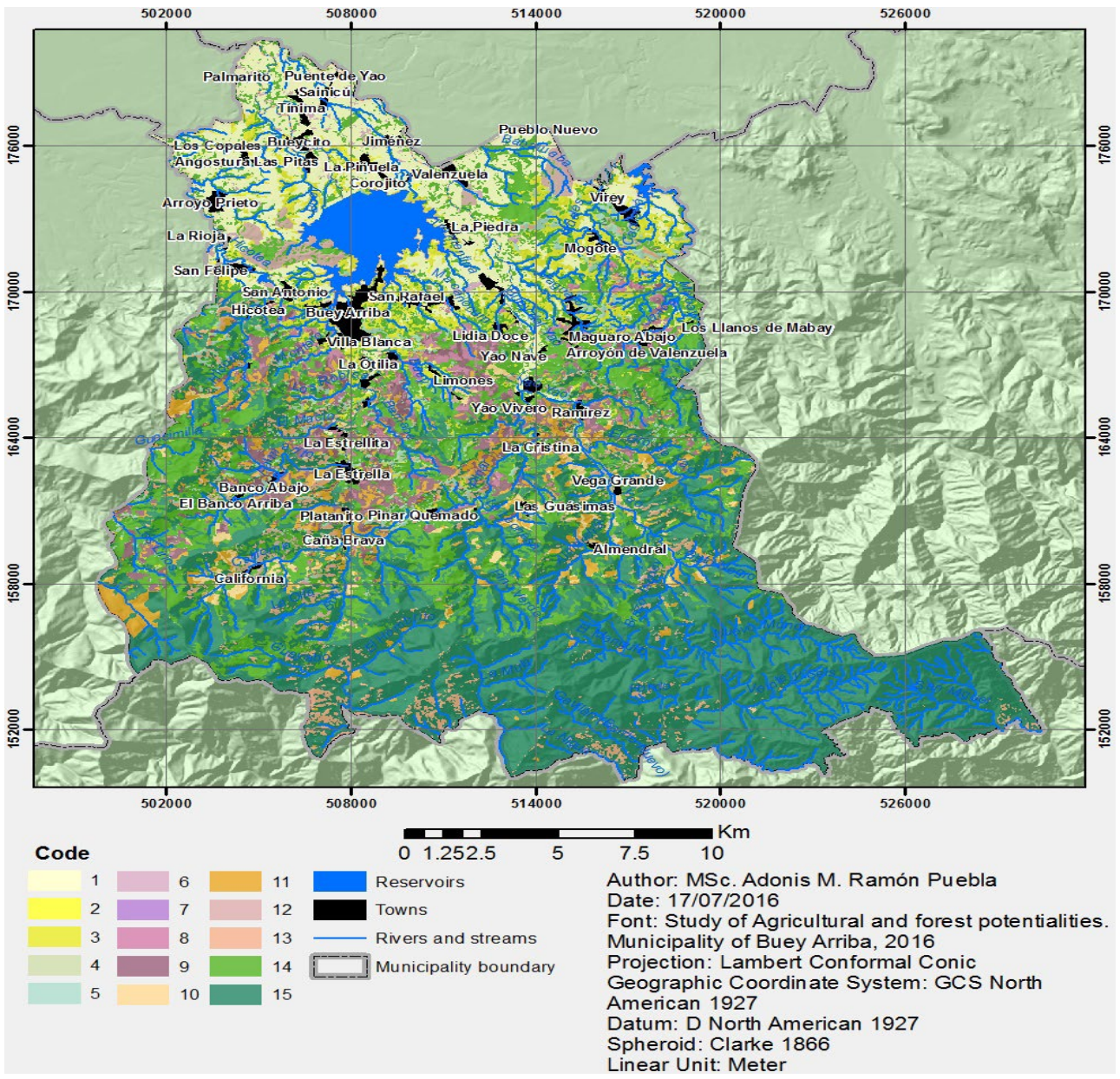

Figura 3. Distribución del potencial agropecuario y silvícola en el municipio Buey Arriba

Fuente: Elaborado por los autores.

\section{Potencial agrícola:}

1. 4582.7 ha de terrenos recomendados para el cultivo de granos, viandas y hortalizas, con pendientes entre $0-8 \%$ y suelos productivos, ocupados actualmente por herbazales, matorrales y áreas de cultivos.

2. 101.7 ha de terrenos recomendados para el cultivo de malanga, calabaza y boniato, con pendientes entre 8-10\% y suelos productivos, ocupados actualmente por herbazales, matorrales y áreas de cultivos.

3. 2263.2 ha de terrenos recomendados para el desarrollo de la ganadería y sistemas 
agrosilvopastoriles, con pendientes entre 10-25\% y suelos productivos, ocupados actualmente por herbazales, matorrales y áreas de cultivos.

4. 60.3 ha de terrenos recomendados para el cultivo café, cacao y frutales, con pendientes entre 25-30\% y suelos productivos, ocupados actualmente por herbazales, matorrales y áreas de cultivos.

5. 2836.9 ha de terrenos recomendados para el cultivo de frutales, café y cacao con pendientes entre 30-50\% y suelos productivos, ocupados actualmente por herbazales, matorrales y áreas de cultivos. En este caso se requiere la aplicación de fuertes medidas de conservación de suelos, en las plantaciones que se prevean establecer.

Existen en el territorio áreas ya establecidas con plantaciones de frutales, café y cacao, que por encontrarse en zonas idóneas para su cultivo se deben mantener, dentro de estas tenemos:

6. 166.5 ha de plantaciones establecidas de frutales, en pendientes entre $0-30 \%$ y suelos productivos.

7. 15.5 ha de plantaciones establecidas de frutales con pendientes entre $30-50 \%$ y suelos productivos, en terrenos que requieren fuertes medidas de conservación de suelos.

8. 914.8 ha de plantaciones establecidas de café y cacao, con pendientes entre 0-30\% y suelos productivos.

9. 2103.2 ha de plantaciones establecidas de café y cacao con pendientes entre 30-50\%, suelos productivos, en terrenos que requieren fuertes medidas de conservación de suelos.

Potencial silvícola:

En el caso del potencial silvícola en algunas áreas de cafetales que se encuentran en terrenos poco adecuados para su rendimiento óptimo el municipio cuenta con:

10. 613.3 ha de terrenos en las que se recomienda el remplazo de plantaciones de café, cacao y frutales por silvicultura para la producción en áreas con pendientes de 0-50\% y suelos poco productivos.

11. 2113.8 ha de terrenos en las que se recomienda el remplazo de plantaciones de café, cacao y frutales por silvicultura para la protección, en áreas con pendientes superiores al 50\%, suelos poco productivos, así como las incluidas dentro de áreas protegidas y las correspondientes a las fajas forestales de las zonas de protección a embalses y cauces fluviales.

Dentro de las áreas con potencial para la reforestación, existen en el territorio áreas que carecen de cobertura boscosa y no son aptas por sus condiciones edafo- geomorfológicas para la actividad productiva, dentro de estas tenemos:

12. 719.1 ha de terrenos recomendados para la reforestación con fines de producción en 
Adonis M. Ramón Puebla Eduardo Salinas Chávez Leusnier Martínez Quintana

MSc. Célida Suarez García

áreas con pendiente de 0-50\%, suelos poco productivos y cobertura de herbazales, cultivos, pastizales y matorrales.

13. 1686.3 ha de terrenos recomendados para la reforestación con fines de protección en áreas con pendiente superiores al 50\%, así como los incluidas dentro de las áreas protegidas y las correspondientes a las fajas forestales de las zonas de protección a embalses y cauces fluviales, con cobertura de herbazales, cultivos, pastizales y matorrales. Dentro de estas fueron identificadas: 101.1 ha en el embalse Bueycito, 16.1 en Pedregales, 3 ha en la micropresa, 74.4 ha en el río Buey y 34.8 en el río Buey del Yao. Se incluyen además 495.1 ha dentro del Parque Nacional "Pico La Bayamesa".

Las potencialidades silvícolas para las áreas que conservan la cobertura boscosa con distintos niveles de degradación por su ubicación y niveles de pendiente, son:

14. 10328.8 ha de bosques con diferentes niveles de degradación, recomendados para la silvicultura de producción, en aquellas áreas con pendiente inferior al 50\%, excluyendo los que se encuentren dentro de las áreas protegidas y de las fajas forestales de las zonas de protección a embalses y cauces fluviales.

15. 18706.9 ha de bosques en diferentes estados de conservación, recomendados para la silvicultura de protección, en aquellas áreas con pendientes superiores al 50\%, así como aquellos que se encuentren dentro de áreas protegidas y las fajas forestales de las zonas de protección a embalses y cauces fluviales

\section{Conclusiones}

A modo de conclusiones se puede establecer que:

- Las condiciones físico-geográficas le confieren al municipio Buey Arriba características particulares que requieren de un profundo análisis para su adecuado aprovechamiento en función de la producción agropecuaria y silvícola.

- La metodología propuesta y el uso combinado de las herramientas que ofrecen los Sistemas de Información Geográfica y la Percepción Remota, permiten modelar y estimar con bastante exactitud los lugares adecuados para el desarrollo agropecuario y silvícola en un territorio dado. Demostrando la validez del método que puede ser adecuado para su aplicación a otras regiones similares de Cuba y el mundo.

- Los análisis realizados de forma colateral como un nuevo producto permitieron evaluar y determinar el estado de la faja hidroreguladora de los embalses, ríos y arroyos del municipio, constituyéndose en una valiosa herramienta para los decisores que intervienen en su protección y rehabilitación.

- Se determinó que el territorio a pesar de ser montañoso, cuenta con amplias potencialidades para el desarrollo agropecuario y silvícola sin violar lo legalmente establecido en la legislación ambiental de nuestro país.

- Finalmente se logra brindar a los decisores locales que intervienen en la entrega de tierras, un mapa digital a escala 1: 25000 de los potenciales agropecuario silvícola 
del municipio, que indica los lugares adecuados para el desarrollo de cada categoría agropecuaria y silvícola del municipio sin comprometer la protección del medio ambiente.

\section{Bibliografía}

Arceo, Sara y Salinas, Eduardo (1994). Evaluación del Potencial natural de los paisajes para la actividad agropecuaria en el ejemplo del municipio de Yagüajay (Provincia de Sancti Spíritus, Cuba) Geographicalia 31, Zaragoza, España Pag. 3-16, Zaragoza.

Benítez, Diocles; Ramírez, Alina y Machado, Braulio (2006). Alternativas tecnológicas para la producción ganadera en las montañas, Instituto de Investigaciones Agropecuarias "Jorge Dimitrov" (inédito).

Bosque, Joaquin (1996). Sistema de Información Geográfica, Madrid, RIALP.

Buzai, Gustavo y Baxendale, Claudia (2012). Análisis Socio espacial con Sistemas de Información Geográfica, Ordenamiento Territorial. Temáticas de base vectorial (tomo 2) Buenos Aires, Lugar.

CONAFOR (2007). Especificaciones técnicas para el monitoreo de la cobertura de la vegetación basado en imágenes de satélite MODIS http://www.conafor.gob.mx/portal/index. php? $11=4 \& 12=3 \& 13=2$ Consultado el 29 de junio de 2009 .

Gaceta Oficial de la República de Cuba (1998). Ley No 85 Ley Forestal, La Habana.

Gaceta Oficial de la República de Cuba (1999) .Resolución No 330 del MINAGRI. Reglamento de la Ley Forestal, La Habana.

Garea, Eduardo; Soto, Francisco; Vantour, Antonio (2006) Combinación de métodos de análisis espacial para la zonificación agroecológica de cultivos en condiciones de montaña, Ciencias de la Tierra y el Espacio, Vol. 7, La Habana, pp.14-28.

Haase, Gunter (1991). Approaches and methods of landscape diagnosis, Ekológia $\square$ SFR 9, pp.3144.

Mannsfeld, Karl (1983). Landschaftsanalyse und Ableitung von Naturraumpotentialen. Abhandl Sächs Akad Wiss zu Leipzig, math-nat Klasse 55(3).

Ministerio de la Agricultura (2003). Manual técnico para las actividades agropecuaria y forestal de las montañas, AGRINFOR, La Habana.

Miraglia, Marina; Caloni, Nicolás y Buzai, Gustavo (Organizadores) (2015). Sistemas de Información Geográfica en la investigación científica actual, Universidad Nacional de General Sarmiento, E-Book.- (Cuestiones metropolitanas).

Montas, Rubén; Rivera, Irving (2006). Estudio bitemporal de la deforestación en la República Dominicana usando sensores remotos, Universidad de Puerto Rico y la Universidad APEC.

Oficina Nacional de Normalización (1999). NC 23:1999 Franjas forestales de las zonas de protección a embalses y cauces fluviales, La Habana.

Oficina Nacional de Normalización (2000). NC 66:2000 Calidad del suelo. Suelos forestales. Clasificación y utilización, La Habana.

Pompa, Maria (2008). Análisis de la deforestación en ecosistemas montañosos del noroeste de México, Avances en Investigación Agropecuaria 12(2) pp. 35-44.

Salinas, Eduardo (1991). Análisis y Evaluación de los Paisajes en la Planificación Regional en Cuba, Tesis de doctorado, Universidad de la Habana.

Salinas, Eduardo; Yanes, Leandro y Arceo, Sara (1990). La Evaluación agropecuaria en la planificación regional en Cuba, Cuadernos Geográficos de la Universidad de Granada No. 18-19, pp. 217-236.

Viña-Dávila, Nicasio; Viña-Bayés, Nicasio; Mustelier, Kesia; Trapero, Adrian y Vicario, Agueda (2000) Caracterización Físico-Geográfica del Macizo Sierra Maestra, BIOECO, Programa Científico Técnico Nacional Desarrollo Sostenible de la Montaña, Santiago de Cuba. 